\title{
Kusz, Veronika. 2020. A Wayfaring Stranger: Ernst von Dohnányi's American Years, 1949-1960. Oakland: University of California Press. 233 pp.
}

\author{
Reviewed by Sarah M. Lucas, Texas A\&M University-Kingsville Sarah.Lucas@tamuk.edu
}

Veronika Kusz's A Wayfaring Stranger: Ernst von Dohnányi's American Years, 1949 1960 is an important contribution to Hungarian Studies, not only in musicology but also for anyone interested in the work of Hungarian émigrés in the United States following the Second World War. This study presents a wealth of primary sources from Dohnányi's estate that had not previously been examined, as well as innovative analyses of some of Dohnányi's late works that have been neglected in the scholarship. Kusz is uniquely positioned to present such a study. She is a Senior Research Fellow at the Center for Twentieth- and Twenty-First-Century Music at the Hungarian Academy of Sciences Institute for Musicology and curator of the Dohnányi Collection there. As part of her graduate studies she carried out research of the Dohnányi materials at Florida State University and at Dohnányi's former home in Tallahassee, Florida, sponsored in part by a Fulbright Grant. The book is indeed an outgrowth of her doctoral dissertation, completed at the Ferenc Liszt Academy in 2009. Materials from Dohnányi's United States estate studied in this book have also appeared in an exhibit prepared by Kusz in the Hungarian Music History Museum of the Hungarian Institute for Musicology in Budapest.

In the first two chapters of A Wayfaring Stranger, Kusz describes Dohnányi's career in Europe and his experiences as an émigré in the U.S. Although he was celebrated as a concert pianist and composer in his early career and later as conductor and music administrator in Hungary, Ernő (Ernst von) Dohnányi’s primary work in the U.S. was as a piano and composition teacher at Florida State University in Tallahassee, Florida. Kusz describes, in the book's first chapter, events leading up to Dohnányi's emigration to the U.S., and she contrasts Dohnányi's prominence and reputation in his European career to his work in America. Dohnányi entered the world stage in 1898 as a concert pianist touring European and American cultural centers. His compositions had already drawn the attention of Johannes Brahms, and later won the Bösendorfer Prize. After a decade in Berlin, Dohnányi established himself as a central figure in Budapest's musical life, as a performer and professor, and later as Music Director of the Hungarian Radio, Director of the Academy of Music, and a member of the Hungarian legislature. Kusz describes the reasons for Dohnányi's departure from Europe and the comparatively low profile Dohnányi managed to establish as an émigré in the American music scene. In 1944 Dohnányi left Hungary for Austria due to political concerns, and in 1945 Dohnányi's legacy was tarnished by scandal. Kusz uses sources never before consulted to explore political charges against Dohnányi. She writes that although the exact charges are unknown, Dohnányi was accused of associating with the fascist Hungarian Arrow Cross Party, an allegation denied by the composer and by many of his colleagues, such as composer Leó Weiner, who wrote letters in his defense. Another prominent Hungarian composer, Zoltán

(cc) BY

ULIS D-Serle
New articles in this journal are licensed under a Creative Commons Attribution 4.0 International License.

This journal is published by the University Library System of the University of Pittsburgh as part of its D-Scribe Digital Publishing Program and is cosponsored by the University of Pittsburgh Press 
Lucas, Sarah M. “Kusz, Veronika. 2020. A Wayfaring Stranger: Ernst von Dohnányi’s American Years, 1949-1960. Oakland: University of California Press. 233 pp." Hungarian Cultural Studies. e-Journal of the American Hungarian Educators Association, Volume 14 (2021) DOI: 10.5195/ahea.2021.449

Kodály, also helped to clear Dohnányi's name. Regardless, the accusation had far-reaching implications for Dohnányi's future. In 1948 he fled Europe for Argentina and in 1949 he settled in the U.S.

Once in America, Dohnányi established relationships with universities, which eventually led to his employment at Florida State University in Tallahassee, Florida. Dohnányi wished to perform in the cultural centers where he had enjoyed success during his earlier American tours, engaging the Hungarian-American music agent Andrew Schulhof, but most of his concerts took place in less prominent locales and venues. Kusz argues that Dohnányi was unable to secure performances in New York due to the scandal that followed him after WWII, even if it was not a recorded reason for cancelled bookings. Kusz shows that articles on his alleged ties to fascist figures and groups appeared in the New York Times and The Boston Sunday Herald, based on a particularly inflammatory article published in the New York Hungarian weekly newspaper $A z$ Ember ['Man'], which presented him as a Nazi collaborator. She points out, however, two other possible explanations for Dohnányi's status in American cultural life. Kusz writes that Dohnányi's conservative musical style may not have been appealing to American audiences interested in new music. As another possible explanation Kusz points out that Dohnányi had to compete with excellent American pianists who may have been in greater demand at the time. His main source of income in his last years was teaching, and although he still performed it was not in the grand halls he had once graced. Kusz provides a chronology of 125 concerts Dohnányi performed during his American years. The concerts, for the most part, took place outside of major cultural centers, in smaller cities and college towns. Kusz notes that while previous Dohnányi biographers Bálint Vázsonyi and Ilona von Dohnányi “saw these appearances as central to the process of rehabilitating the composer as an artist and a man," she disputes this view, arguing that "the venues were unstrategic" and "the momentous successes were in fact lacking" (33).

Using primary sources from Dohnányi's estate, Kusz explores Dohnányi’s financial situation in Florida, demonstrating that the Dohnányis had to adapt to a lower standard of living in the U.S. than what they had previously enjoyed in Hungary. She compares his financial struggles to those of another important Hungarian composer-pianist who had also immigrated to the U.S. about a decade before Dohnányi-Béla Bartók — noting that Dohnányi managed to establish a more reliable source of income than did Bartók. Kusz's comparison of the two composers could be extended to include further general comparisons of their experiences, and perhaps these are of some interest. Both Dohnányi and Bartók worked with the HungarianAmerican music agent Andrew Schulhof to arrange American performances. Bartók had also toured the U.S. in the 1920s, performing primarily his own piano works but, unlike Dohnányi, he had not received such overwhelmingly positive reviews. Both composers were commissioned to write pieces in the U.S., but Dohnányi's commissions were of a relatively low profile. For most of his American years Bartók lived in a cultural center, while Dohnányi did not, and he had established connections with major universities such as Columbia and Harvard, albeit on a temporary basis. In contrast, Dohnányi, in addition to his post at Florida State University, took up temporary residencies at several other universities and established a special connection with the president of Ohio University. In association with Dohnányi's work at Florida State, Kusz also reveals his frustrations at ending his career as a teacher. Central to Kusz's argument, however, is her belief that although Dohnányi's profile and financial situation were significantly reduced in the U.S. compared to his stature in Hungary, correspondence and other sources show that he 
maintained his characteristically cheerful demeanor both in his personal life and in his professional engagements.

Although Dohnányi's performance career was perhaps not what he had hoped it would be in the U.S., he did complete several compositions during his American years, and Kusz analyzes these works in Chapters Three to Five. Her book's title comes from one of the American songs Dohnányi used as source material for one of his most significant compositions of the period American Rhapsody. Kusz also analyzes his Stabat Mater, as well as Three Singular Pieces for Piano, op. 44, Aria for Flute and Piano, Passacaglia for Solo Flute, Violin Concerto no. 2, and his Concertino for Harp and Chamber Orchestra. These analysis chapters are particularly compelling. Kusz introduces each composition with an examination of pertinent primary materials related to a variety of topics such as reception, Dohnányi's religious beliefs, and possible influences on Dohnányi's compositional style in his late career. Kusz further examines Dohnányi's attitude toward modernism in music, and considers Bartók's compositional style as a model for some of the modern elements in Dohnányi's late works, such as the Passacaglia for Flute, which is in part dodecaphonic (using a twelve-tone technique). By applying these points of introduction to the analysis chapters, and through her thorough examinations of musical materials, Kusz distinguishes her analyses of Dohnányi's American works from those carried out previously. Additionally, this approach to analysis makes the entirety of the book more accessible to scholars in fields outside of music. Enhancing her analyses are numerous tables and annotated score excerpts.

Kusz's Epilogue explores Dohnányi's pianistic legacy through an analysis of his recordings. Dohnányi left behind fewer recordings of his own playing than other performers of his time due to his negative feelings regarding recording as opposed to live performances. It is all the more significant, then, that Kusz offers commentary on recordings of the composer playing his own works, held in Dohnányi's estate. The recordings reveal that when Dohnányi played in studio recordings his approach was less spontaneous than in recordings of his live performances. Kusz concludes that Dohnányi also made alterations in his compositional approach in response to his drastic change of circumstances at the end of his career, seeming to reconsider and experiment in his music with varying degrees of success. Four appendices follow the main text, including a chronology of Dohnányi's Life in the United States, Main Specification of Dohnányi's American Works, Dohnányi’s Concerts in the United States, and Dohnányi's Concert Repertoire in the United States.

Kusz's approach to the analysis of Dohnányi's late works differs from that of previous studies in that it considers sources that were never before considered in this context. Kusz reconsiders Dohnányi biographies and memoirs in light of new primary sources, even demonstrating that some sections of Dohnányi's Message to Posterity and Farewell and Message may have been added by Ilona Dohnányi, the composer's third wife. This book is valuable to music scholars and to those interested in Hungarian topics in fields outside of music; and even in analysis chapters, where the work is most technical, Kusz provides context that is accessible and of interest to non-specialists. 